\title{
Copper Oxidation through Nucleation Sites of Chemical Vapor Deposited Graphene
}

Luo, Birong; Whelan, Patrick Rebsdorf; Shivayogimath, Abhay; Mackenzie, David; Bøggild, Peter; Booth, Tim

Published in:

Chemistry of Materials

Link to article, DOI:

10.1021/acs.chemmater.6b00752

Publication date:

2016

Document Version

Peer reviewed version

Link back to DTU Orbit

Citation (APA):

Luo, B., Whelan, P. R., Shivayogimath, A., Mackenzie, D., Bøggild, P., \& Booth, T. (2016). Copper Oxidation through Nucleation Sites of Chemical Vapor Deposited Graphene. Chemistry of Materials, 28(11), 3789-3795. https://doi.org/10.1021/acs.chemmater.6b00752

\section{General rights}

Copyright and moral rights for the publications made accessible in the public portal are retained by the authors and/or other copyright owners and it is a condition of accessing publications that users recognise and abide by the legal requirements associated with these rights.

- Users may download and print one copy of any publication from the public portal for the purpose of private study or research.

- You may not further distribute the material or use it for any profit-making activity or commercial gain

- You may freely distribute the URL identifying the publication in the public portal 


\title{
Copper Oxidation through Nucleation Sites of Chemical Vapor Deposited Graphene
}

\author{
Birong Luo ${ }^{\dagger}$, Patrick R. Whelan ${ }^{\dagger}$, Abhay Shivayogimath ${ }^{\dagger}$, David M. A. Mackenzie ${ }^{\dagger}$, Peter Bøg- \\ gild $^{\dagger, \S}$, and Timothy J. Booth ${ }^{*} \dagger$ \\ ${ }^{\dagger}$ DTU Nanotech, Technical University of Denmark, Ørsteds Plads, 345E, Kgs. Lyngby, 280o Denmark. \\ ${ }^{\S}$ Center for Nanostructured Graphene (CNG), Technical University of Denmark, Kgs. Lyngby, 280o Denmark
}

\begin{abstract}
We investigate the nucleation defect-triggered oxidation of $\mathrm{Cu}$ covered by CVD graphene during post-annealing in air. The results reveal that different growth conditions may induce imperfect nucleation of graphene, and cause creation of defects near the nucleation point such as pin holes and amorphous carbon. These defects would serve as a pathway for the diffusion of $\mathrm{O}_{2}$ during thermal annealing, allowing oxidation of $\mathrm{Cu}$ to progress gradually from the nucleation center towards the growth edge. The oxidation process follows the graphene morphology closely; the shape of the oxidized area of $\mathrm{Cu}$ has a striking resemblance to that of the graphene flakes. Our work demonstrates that inferior graphene nucleation in CVD processes can compromise the oxidation resistance of a graphene coated $\mathrm{Cu}$ substrate, and indirectly reveal the structure and integrity of graphene, which is of fundamental importance for the quality monitoring and control of graphene growth, for understanding the mechanisms of graphene nucleation and growth, and has implications for graphene's use in electronic and passivation applications.
\end{abstract}

\section{INTRODUCTION}

Process control of the chemical vapor deposition (CVD) growth of graphene on $\mathrm{Cu}$ is critical for achieving high quality and throughput in graphene production. A typical CVD process for graphene synthesis consists of two stages: nucleation of individual graphene crystallites on the surface of $\mathrm{Cu}$, followed by accretion growth at the edges. With this two-dimensional growth process, these randomly distributed graphene nuclei grow together and eventually create a polycrystalline film composed of numerous grain boundaries. To reduce grain boundaries in graphene film, intensive efforts have been made in developing strategies to reduce the nucleation density and accurately control the growth kinetics ${ }^{1-6}$, and even to nucleate highly oriented graphene domains so that separate domains grow together into a seamless single-crystal ${ }^{7-9}$. In other words, nucleation of graphene can determine the graphene domain sizes and the frequency of grain boundaries in the graphene film, which, in turn, can play a crucial role in the material quality such as carrier mobility, mechanical properties and thermal conductivity ${ }^{2,10-11}$.

At the same time, it is also important to understand where the nucleation sites occur. Generally, it is believed that the locations of the nucleation sites of graphene on $\mathrm{Cu}$ are determined by the presence of imperfections on $\mathrm{Cu}$ substrates such as step edges ${ }^{12-13}$, defects ${ }^{14-15}$, and surface impurities. ${ }^{6}{ }^{16-17}$ Nucleation proceeds by the formation of chains of carbon atoms and clusters of sp2 bonded carbon at imperfections on the $\mathrm{Cu}$ surface in the initial stage of growth, and have been found to be largely dependent on growth parameters like temperature and system pressure. ${ }^{18-19}$ Indeed, it is evident that different reaction conditions - gas partial pressures, temperature and time - influence the different gas-phase reactions and dynamics, which are critical for the nucleation and the subsequent growth of graphene and further influence the layer uniformity $^{20}$, and can result in highly defected graphene ${ }^{21}$. Thus, the initial nucleation stage of graphene in the CVD process largely determines the quality of the graphene at the growth stage, since disorder locked-in early on limits the quality of the subsequent growth. However, the effect of this disorder at the nucleation site on the quality of the graphene film, and in particular the effect of disordered graphene at the nucleation site on the properties of graphene as e.g. a barrier coating against oxidation of $\mathrm{Cu}$ remain unexplored.

In this work, oxidation of $\mathrm{Cu}$ through a layer of CVD grown graphene is used to assess the quality of CVD graphene growth via optical microscopy - oxidized copper regions are readily visible in the optical microscope and allow unequivocal identification of areas where graphene is permeable or absent. Our findings suggest that the initial CVD conditions are critical for the nucleation of graphene, and subsequently determine the formation of defects such as pin holes and accumulated amorphous carbon. This plays a significant role in the thermal oxidation of graphene and the underlying $\mathrm{Cu}$ substrate in air. It is shown that the oxidation starts from the nucleation site of graphene, before proceeding along the graphene-copper interface. This oxidation along the graphene-copper interface progresses according to the graphene morphology, 
giving rise to striking similarities in the morphology of graphene and copper oxide structures. Our results demonstrate the oxidation behavior of $\mathrm{Cu}$ coated by CVD graphene (whether partial or full-coverage growth) is highly correlated with graphene crystal morphology and defect density, particularly at the nucleation center of the crystallite, and that this is of fundamental importance in understanding the mechanism of graphene barrier properties and for mechanical and electrical applications of CVD graphene.

\section{EXPERIMENTAL SECTION}

CVD synthesis. Cu foils (99.8\% purity, $25 \mu \mathrm{m}$ thick, Alfa Aesar) were electropolished according to a method described previously ${ }^{22}$ and then used as growth substrates within an Aixtron Black Magic cold wall CVD system. After an annealing process in a hydrogen/argon atmosphere, growth is initiated by introducing a methane $\left(\mathrm{CH}_{4}\right)$ feedstock and hydrogen $\left(\mathrm{H}_{2}\right)$ carrier gas in the chamber. The annealing was performed in a mixture of $1000 \mathrm{sccm}$ (standard cubic centimeters per minute) $\mathrm{H}_{2}$ and $1000 \mathrm{sccm}$ argon (Ar) for $30 \mathrm{~min}$ in all cases. Both annealing and growth were performed at low pressure (20 mbar). The samples with inferior nucleation were grown on the electropolished $\mathrm{Cu}$ surface in $\mathrm{CH}_{4}(2 \mathrm{sccm})$ diluted with $\mathrm{H}_{2}(50 \mathrm{sccm})$ at $900{ }^{\circ} \mathrm{C}$ for 5-30 min growth. High quality nucleation and growth was achieved either by increasing the growth temperature to $1000{ }^{\circ} \mathrm{C}$, or reducing the flow rate of $\mathrm{CH}_{4}$ to 0.5 sccm for the growth while keeping the other CVD conditions unchanged.

Transfer of graphene. A $5 \mu \mathrm{m}$ sacrificial layer of cellulose acetate butyrate (30 $\mathrm{kDa}, 0.3 \mathrm{~g} / \mathrm{l}$ in ethyl acetate) (CAB), is spun (10oo rpm, 6o s) on the Cu substrates after graphene growth, then baked at $100{ }^{\circ} \mathrm{C}$ for $30 \mathrm{~min}$. Graphene on the back side of the foils is removed by oxygen plasma (5o W, 2 min). Subsequently, electrochemical generation of hydrogen bubbles at the graphene copper interface $^{23-24}$ was employed to transfer graphene from $\mathrm{Cu}$ surfaces onto $300 \mathrm{~nm} \mathrm{SiO}_{2} / \mathrm{Si}$ substrates. The $\mathrm{CAB}$ polymer support layers were finally dissolved with hot acetone, leaving the graphene layers adhered to the $\mathrm{SiO}_{2} / \mathrm{Si}$ substrates.

Characterization of graphene. Scanning electron microscopy (SEM) (Zeiss Supra VP 6o, 1o kV) equipped with EDX was used to characterize the morphology and measure the elemental distribution of as-produced graphene before and after thermal annealing in air. A Nikon Eclipse L20o microscope equipped with a programmable Prior Scientific XYZ stage and a 5-10ox objective with NA $=0.3$ (o.484 $\mu \mathrm{m} /$ pixel @ 10oX) is used to observe the transformation of oxidation of $\mathrm{Cu}$ covered by graphene. Atomic force microscope (AFM) (Dimension Icon-PT from Bruker AXS) was used to observe the morphology and height profile of as-synthesized graphene before and after transfer. Raman spectra and Raman mapping were performed with a Thermo Fisher DXR microscope under ambient conditions using a $455 \mathrm{~nm}$ excitation laser source. The nominal spot size is $700 \mathrm{~nm}$. The power of the laser is kept below 1
$\mathrm{mW}$. X-ray photoelectron spectroscopy (XPS) measurements were performed with an Escalab 22oi-XL from Thermo Scientific. A monochromatized Al K-Alpha X-ray source with photon energy $1486.7 \mathrm{eV}$ was used as photon source.
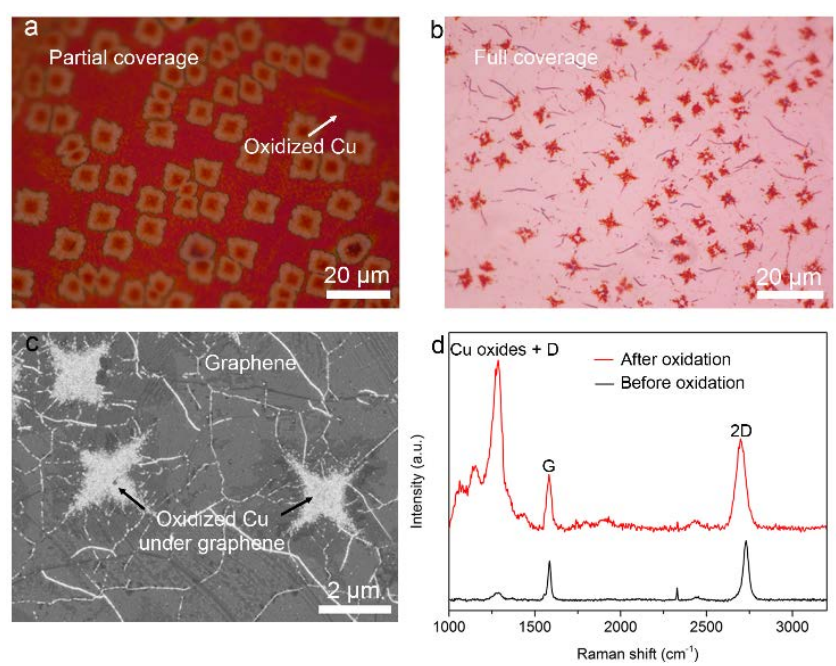

Figure 1. Optical microscopic images of (a) partial-coverage graphene grains and (b) full-coverage graphene films on $\mathrm{Cu}$ foil after thermal oxidation at $250^{\circ} \mathrm{C}$ for $20 \mathrm{~min}$ in air. (c) A magnified SEM image of the $\mathrm{Cu}$ foil with graphene films coating after thermal oxidation at $250^{\circ} \mathrm{C}$ for $20 \mathrm{~min}$ in air. (d) The Raman spectra of $\mathrm{Cu}$ foil with graphene coating before and after thermal oxidation at $250^{\circ} \mathrm{C}$ for $20 \mathrm{~min}$ in air.

\section{RESULTS AND DISCUSSION}

We synthesized partial-coverage and full-coverage graphene films on $\mathrm{Cu}$ foils by CVD using a $\mathrm{CH}_{4}$ precursor and varying the growth time. Optical microscopy is used to study the morphology and structural quality of the as-synthesized graphene by oxidizing the underlying $\mathrm{Cu}$ substrate through defects at $250^{\circ} \mathrm{C}$ in air. As perfect graphene is thermally/chemically stable at this temperature in air and impermeable to all atoms and molecules ${ }^{25}$, in the ideal case of full coverage pristine graphene the $\mathrm{Cu}$ surface would be protected from oxidation and the graphene itself would not be damaged by oxidation. Any deviation from pristine graphene in close contact with $\mathrm{Cu}$ leads to oxidation-induced color changes in the copper surface clearly visible in the optical microscope. Defects such as grain boundaries ${ }^{26}$ and wrinkles ${ }^{27}$ can for instance act as channels for the oxygen diffusion, and are clearly visible during the oxidation.

Based on this, the structural quality of graphene can be assessed via optical microscopy. As shown in Figure 1a, asgrown tetragonal graphene grains are randomly distributed on the $\mathrm{Cu}$ foil as a result of the CVD growth process, and are clearly visible after thermal oxidation in air at 250 


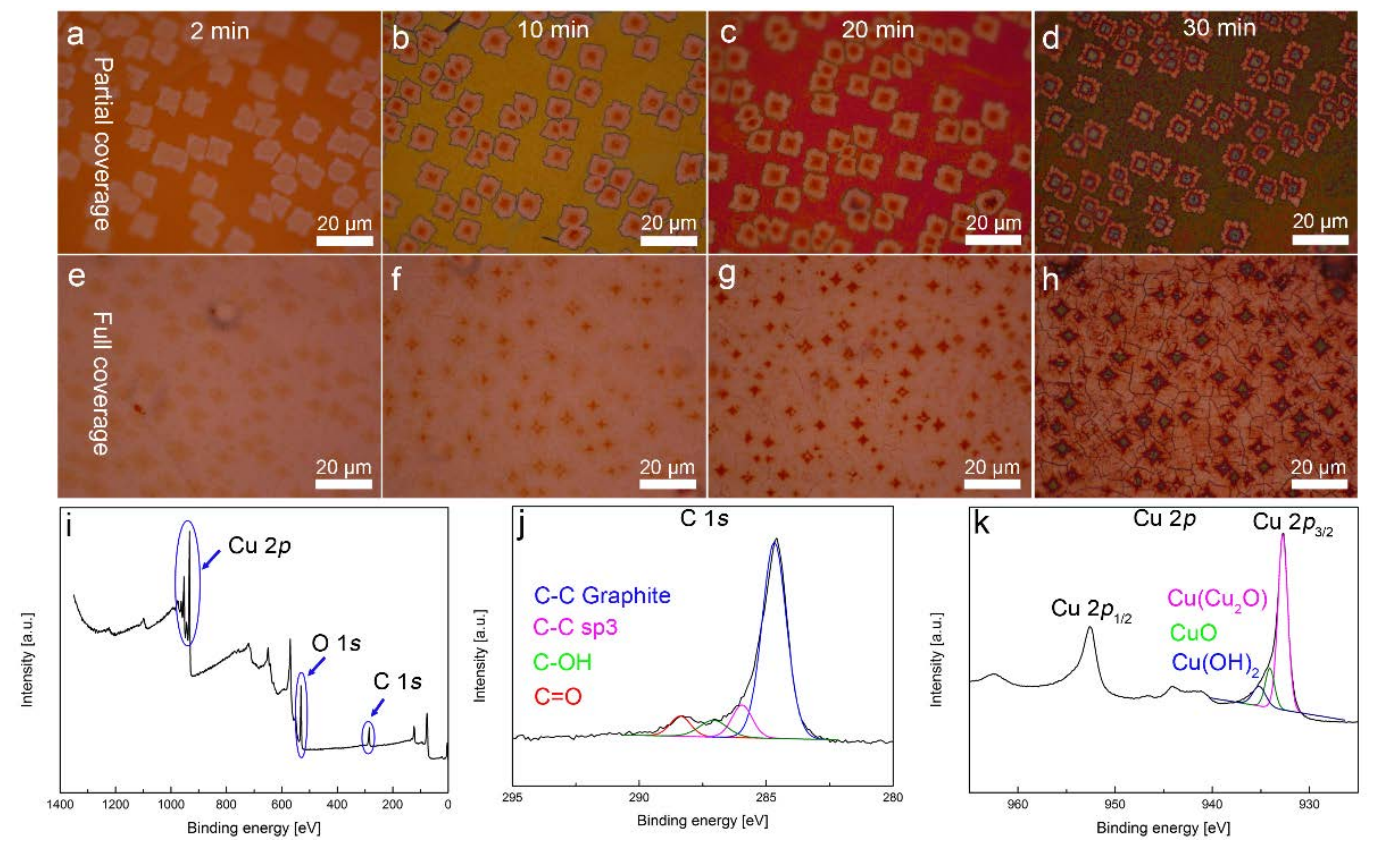

Figure 2. (a-d) Optical images of partial and (e-h) full coverage graphene films after thermal oxidation in air by varying the annealing time from $2-30 \mathrm{~min}$ at $250^{\circ} \mathrm{C}$. (i) Typical $\mathrm{x}$-ray photoelectron spectroscopy scan survey showing copper, oxygen, and carbon. (j) XPS core-level $\mathrm{C}$ is spectrum of $\mathrm{Cu}$ foil with graphene after thermal oxidation. (k) XPS core-level Cu $2 p$ spectrum of $\mathrm{Cu}$ foil with graphene after thermal oxidation.

${ }^{\circ} \mathrm{C}$ for $20 \mathrm{~min}$. The optical image shows the commonly observed apparent contrast from the bare copper surface to graphene grains due to different degree of oxidation. In particular, the individual graphene grains with oxidationinduced pattern from center to the edge tend to align over a large area (Figure $\mathrm{S}_{1}$ ), showing high reproducibility and high yield of the oxidation process. We note that the copper near the graphene nucleation sites seems to be more severely oxidized than near the graphene edge. This can be explained by defects at the nucleation sites allowing diffusion of oxygen to the copper surface. This effect can be observed more clearly in the full-coverage graphene sample (Figure $1 b$ ). As shown in Figure $1 b$, oxidized areas of the copper are distributed over the graphene films, which correspond to the most probable distribution of nucleation sites. Interestingly, the oxidized shape associated with the nucleation site is quite similar to the shape of graphene grains in Figure 1a. This can be confirmed in the magnified scanning electron microscopy (SEM) showed in Figure 1c. Raman spectra (Figure 1d) of the graphene before and after oxidation also show some differences. Both spectra of graphene before and after oxidation show the characteristic $2 \mathrm{D}$ and $\mathrm{G}$ peaks. Distinctive features arise around the graphene $\mathrm{D}$ peak region, but associated with $\mathrm{Cu}$ oxides in the oxidized samples, indicating that the oxidation has affected the areas with imperfect graphene. At the same time, the $G$ and $2 \mathrm{D}$ peaks undergo red shifts by $2 \mathrm{~cm}^{-1}$ and $29 \mathrm{~cm}^{-1}$, respectively.

Figure 2 shows the evolution of the thermal oxidation of graphene with different oxidation time in air at the same thermal annealing temperature $\left(250^{\circ} \mathrm{C}\right)$. As illustrated, the
$\mathrm{Cu}$ surfaces grown with incomplete (Figure 2a-d) and complete coverage of graphene (Figure ze-h) show increasingly apparent oxidation around the nucleation site with increased annealing time at $250^{\circ} \mathrm{C}$. This indicates that the oxidation starts from graphene nucleation sites and proceeds parallel to the graphene- $\mathrm{Cu}$ interface, with the continuous formation of oxides at the nucleation sites throughout the 2-30 min oxidation process. X-ray photoelectron spectroscopy (XPS) was used to analyze the surface composition of the samples after annealing. We choose the full-coverage sample annealed for $20 \mathrm{~min}$ at $250{ }^{\circ} \mathrm{C}$ in air for the analysis. As shown in Figure 2i, a typical survey scan shows the sample after annealing contains oxygen, carbon, and copper, as expected. The $\mathrm{C}$ is spectrum (Figure 2j) mostly exhibits an asymmetric shape typical of graphitic $s p 2$ carbon with a binding energy of $284.6 \mathrm{eV}$. The remainder of the spectrum can be fit by $\mathrm{C}-\mathrm{C} s p 3(284.8 \mathrm{eV})$, hydroxyl C-OH $(286.3 \mathrm{eV})$, carbonyl $\mathrm{C}=\mathrm{O}(288.1 \mathrm{eV})$. The $\mathrm{Cu}$ $2 p$ spectrum consists of several peaks after annealing, which correspond to the formation of different $\mathrm{Cu}$ oxides: $\mathrm{Cu}_{2} \mathrm{O}(932.5 \mathrm{eV})$ which is very close to $\mathrm{Cu}(932.6 \mathrm{eV}), \mathrm{CuO}$ $(933.7 \mathrm{eV})$ and $\mathrm{Cu}(\mathrm{OH})_{2}(934.7 \mathrm{eV})$. In addition, energy dispersive X-ray spectroscopy (EDS) was also performed on partial coverage graphene samples for the elemental analysis. We choose different spots located at graphene nucleation site, graphene edge, and $\mathrm{Cu}$ surface for the analysis. The locations analyzed are mainly composed of carbon, oxygen, and copper, as shown in the EDX spectra (Figure S2). However, the oxygen content differs. The exposed $\mathrm{Cu}$ surface shows the strongest oxygen signal while graphene edges do not show any clear oxygen signal, which is reasonable for samples oxidized in air because graphene can protect the underlying $\mathrm{Cu}$ from oxidation. We note that 
the graphene nucleation sites have a moderate oxygen signal due to the oxidized $\mathrm{Cu}$ beneath graphene. Figure $\mathrm{S}_{3}$ shows results for the elemental mapping of graphene films. As expected, the elemental distribution of oxygen corresponds very well with the distribution of nucleation sites of graphene. These results agree well with the observation in optical microscopy above, confirming that the rapid thermal oxidation of $\mathrm{Cu}$ with graphene in air starts from graphene nucleation sites due to defects formed during the nucleation process in CVD.
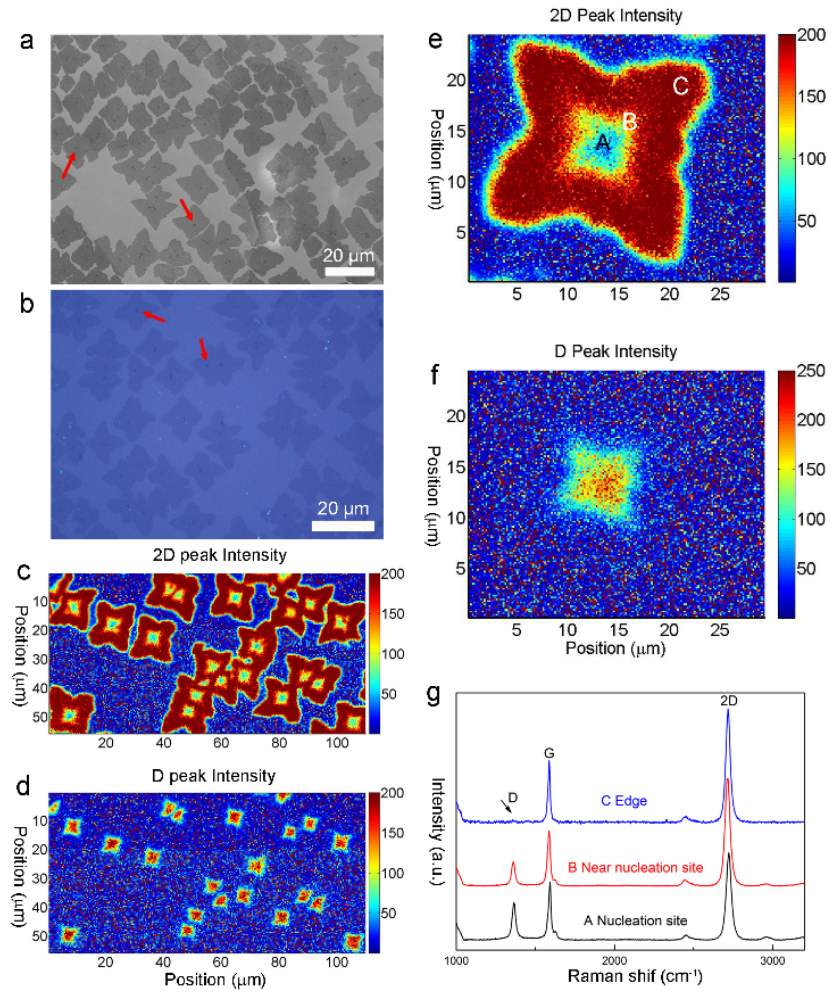

Figure 3. (a) SEM image of as-synthesized graphene grains without annealing. (b) Optical image of as-synthesized graphene grains transferred onto the $\mathrm{SiO}_{2} / \mathrm{Si}$ substrate. (c, d) Raman mapping of the $2 \mathrm{D}$ and $\mathrm{D}$ band intensity of graphene grains transferred onto $\mathrm{SiO}_{2} / \mathrm{Si}$ substrate. (e, f) Raman mapping of the $2 \mathrm{D}$ and $\mathrm{D}$ band intensity of an individual graphene grain transferred onto $\mathrm{SiO}_{2} / \mathrm{Si}$ substrate. (g) Raman spectra of the different area as labeled A, B, and $\mathrm{C}$ in (e).

To further understand the origin and distribution of graphene defects around the graphene nucleation site and why oxidation of $\mathrm{Cu}$ is so prevalent in these areas during the post-growth thermal oxidation, the as-synthesized graphene grains without oxidation were transferred onto $\mathrm{SiO}_{2} / \mathrm{Si}$ substrates and characterized by Raman spectroscopy. As shown in Figure za and b, SEM image of graphene grains before transfer correspond well to optical images of graphene grains after transfer, showing close to $100 \%$ yield of transfer. In addition, the graphene nuclei can be clearly discriminated both in the SEM and optical images, displaying higher contrast areas, marked by the red arrow in Figure $3 a$ and b. Furthermore, Raman spectroscopic characterization can provide detailed information on the quality of graphene ${ }^{28}$. Figure $3 c$ and d show micro-Raman spatial mapping of the $2 \mathrm{D}$ and $\mathrm{D}$ peaks which negatively correlate over a 100x50 $\mu \mathrm{m}$ area, showing locally reduced $2 \mathrm{D}$ peak and increased $\mathrm{D}$ peak intensity at graphene nuclei, with the $2 \mathrm{D}$ peak increasing and the $\mathrm{D}$ peak decreasing towards the edge of the graphene domains. This heterogeneity in the distribution of defects and graphene quality is clearly demonstrated in the high-magnification micro-Raman maps of an individual graphene grains (Figure $3 \mathrm{e}$ and $\mathrm{f}$ ). Raman spectra for the areas labeled A, B, and C in Figure ze - which correspond to the nucleation site, near the nucleation site, and leading edge of the growth front respectively - exhibit typical characteristics of single-layer graphene with increasing intensity of $\mathrm{D}$ peak closer to the center of the graphene grain. This indicates a high density of defects around the graphene domain nuclei during the CVD process, with gradually improving quality towards the graphene grain edges.

As shown in Figure 4a, the SEM image shows that the morphology of oxidized $\mathrm{Cu}$ follows the growth morphology of the graphene grain. To reveal the details of the nuclei, we carried out the atomic force microscope (AFM) measurement of graphene transferred onto $\mathrm{SiO}_{2} / \mathrm{Si}$ substrate (Figure $4 \mathrm{~b}$ ). The AFM image shows the four-lobed morphology of a tetragonal graphene grain, with uniform height distribution. The height of the graphene lobe with respect to the substrate is found to be $\sim 0.86(13) \mathrm{nm}$ at the right hand edge, which is in accord with reports ${ }^{29}$ for oneatom-thick graphene on $\mathrm{SiO}_{2} / \mathrm{Si}$ substrates. More distinctive features arise at the nucleus of the transferred graphene grain, showing a hill-like topography. This is clearly seen in the magnified AFM image (Figure 4c) taken from the region of the graphene nucleation center. As shown, the height of the nucleus is found to have a parabolic profile and a maximum height of $\sim 36 \mathrm{~nm}$. This indicates that the nucleation point is composed of some impurities/defects such as an accumulation of amorphous carbon rather than graphene, making it weaker protection against to the $\mathrm{Cu}$ substrate. Alternatively, the nucleation point could be composed of a buried impurity nanoparticle transferred from the $\mathrm{Cu}$ catalyst layer, which distorts the graphene lattice and acts as a secondary catalyst site for the oxidation of the underlying $\mathrm{Cu}$ and possibly the neighboring graphene.

Based on these observations, we have concluded that the nucleation process during CVD is responsible for the oxidation preference of $\mathrm{Cu}$ around graphene nucleation sites, with defected graphene at the nucleation center acting as a poor barrier against $\mathrm{Cu}$ oxidation. The proposed nucleation-growth mechanism and associated influence on their oxidation is illustrated in Figure 4d. CVD graphene grows on the $\mathrm{Cu}$ surface via a nucleation-growth mechanism and is predominantly single-layer owing to the self-limiting growth effect..$^{\circ}$ Methane is broken down through dissociative chemisorption on the $\mathrm{Cu}$ surface, and the concentration of the dissociated carbon species increases and reaches a critical level, where the carbon species aggregate into small critical nuclei at appropriate sites. Then the nuclei continue to enlarge over the surface into graphene grains. Nucleation occurs preferentially at low-energy sites 
such as terraces ${ }^{12-13}$ and nanoparticles ${ }^{16-17}$ on $\mathrm{Cu}$ surface which serve as the nucleation sites for graphene growth (Figure $\mathrm{S}_{4}$ ).
In addition to thermally assisted oxidation of graphene coated $\mathrm{Cu}$ in air, we also studied the slow oxidation behavior of our graphene on $\mathrm{Cu}$ foil at room temperature by exposure to the atmospheric environment for a long duration

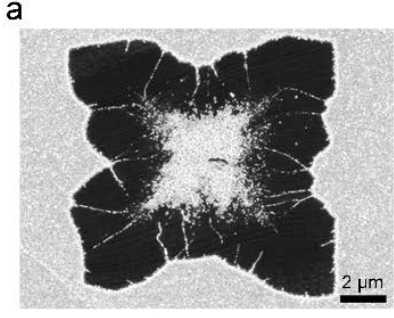

d
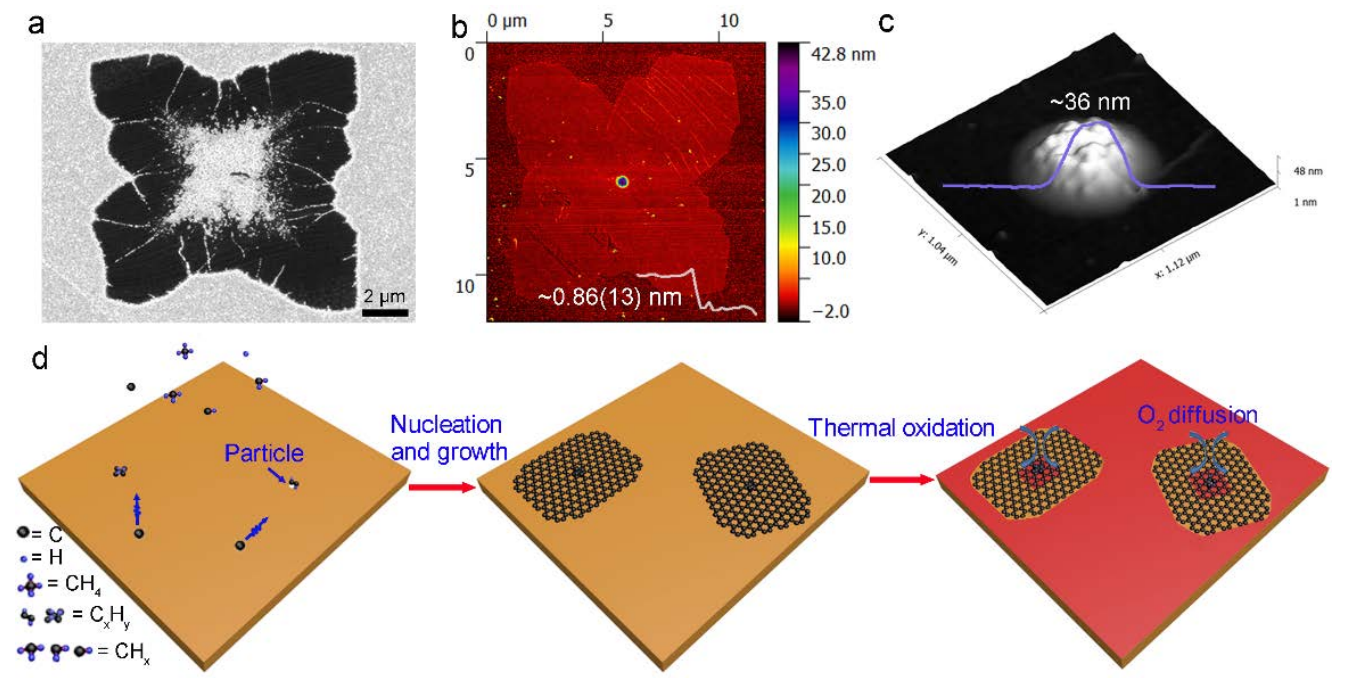

Figure 4. (a) A magnified SEM image of an individual graphene grain after thermal annealing in air. (b) AFM image of an individual graphene grain after transferred onto $\mathrm{SiO}_{2} / \mathrm{Si}$ substrate. (c) A magnified AFM image of the nucleation site of the graphene grain transferred onto $\mathrm{SiO}_{2} / \mathrm{Si}$ substrate. (d) A schematic illustration showing the full process of nucleation, growth and thermal annealing mechanisms.

The rapid growth of graphene at such nucleation centers is apt to form defects ${ }^{31-32}$, which allows $\mathrm{O}_{2}$ to enter and oxidize the $\mathrm{Cu}$ below. It should also be noted that different CVD conditions like temperature, system pressure and gas flow rate would also affect the nucleation process, leading the inferior nucleation and formation of defects. Here our experiments typically use a $\mathrm{CH}_{4}$ gas feedstock mixed with $\mathrm{H}_{2}$ flowing over a heated $\mathrm{Cu}$ foil in a cold wall CVD system. The elevated temperature of $\mathrm{Cu}$ (both on the target substrate and the vapour-phase contaminant in the chamber when condensed on the cold walls of the system) is expected to catalyze gas phase reactions, driving the gaseous composition toward the formation of higher order $\mathrm{C}_{x} \mathrm{H}_{y}$ species. ${ }^{21}$ Such gas phase reactions, which are time- and temperature-dependent and define the lowest energy configuration of a thermodynamic equilibrium under specific CVD condition, is also the initial step in the reaction pathway for graphene formation by nucleation. The formation of higher order $\mathrm{C}_{\mathrm{x}} \mathrm{H}_{\mathrm{y}}$ species from methane feedstock is likely to be critical for the nucleation, and the disordered incorporation of these higher order hydrocarbons into the nucleation center of the graphene grain is probably the origin of the higher defect density here. In other words, incomplete breakdown and higher order hydrocarbon species cause the formation of defects such as pin holes and accumulation of amorphous carbon in the initial stage of nucleation (Figure $4 \mathrm{~d}$ and Figure $\mathrm{S}_{5}$ ). This imperfect nucleation plays a significant role in the thermal oxidation of graphene and $\mathrm{Cu}$ in the air as shown here. Oxidation starts from the nucleation site of graphene then progresses in the 2D plane, because oxygen from the air diffuses through such defects more easily (Figure $4 \mathrm{~d}$ and Figure $\mathrm{S}_{5}$ ).
(3 months). We observed some differences in oxidation mechanism of $\mathrm{Cu}$ foil compared to thermally assisted oxidation. Figure S6 a shows an optical image of graphene grains on $\mathrm{Cu}$ foil exposed to ambient conditions at room temperature for 3 months. It can be seen that besides a similar oxidation effect occurring at nucleation sites, the oxidation of $\mathrm{Cu}$ foil simultaneously occurs with diffusion of $\mathrm{O}_{2}$ through the reactive grains edges, which is accordance with other reports ${ }^{32-33}$. This oxidation from the edges is seen in SEM (Figure S6 b and c) and AFM images (Figure S6 e). Meanwhile, magnified AFM images (Figure S6 e and f) display the oxidized surface topology in the nucleation site.

As described above, a combination of copper impurityassisted nucleation and gas phase reactions involved in CVD conditions causes the formation of defects during graphene nucleation. However, the $\mathrm{Cu}$ foils employed for the growth in our experiments have been electropolished to reduce the $\mathrm{Cu}$ surface imperfections as far as possible. Even so, the produced graphene still shows a similar nucleation defect-triggered oxidation of $\mathrm{Cu}$ below the graphene across the surface. Thus, we suggest that here the typical defects formed during the initial stage of nucleation of graphene are dominated by the CVD conditions, namely the formation of higher order hydrocarbons in the gas phase. In principle, the perfect nucleation and growth of graphene on copper proceeds by the formation of chains of carbon atoms and then clusters of sp2 bonded carbon at the nucleation site, and has been found to be largely independent of impurities and the $\mathrm{Cu}$ facet on which growth occurs (Figure $5 \mathrm{a}$ and $\mathrm{b}$ ). Considering the relatively low tempera- 
ture $\left(900^{\circ} \mathrm{C}\right)$ used in our experiments, this would cause incomplete decomposition of feedstock molecules and any higher order hydrocarbon species, inducing imperfect nucleation of graphene in the CVD process. When increasing the growth temperature to $1000^{\circ} \mathrm{C}$, the graphene nucleates and grows on the $\mathrm{Cu}$ surface with much better quality (Figure $5 \mathrm{c}$ and d). As shown in the optical image (Figure $5 \mathrm{c}$ ), the synthesized graphene has a much larger domain size than for the lower temperature growth. Figure $5 \mathrm{~d}$ shows the magnified SEM image of an individual graphene grain after annealing in the air for $20 \mathrm{~min}$ at $250{ }^{\circ} \mathrm{C}$ : oxidation does not occur at the nucleation site. In addition, by reducing the flow rate of feedstock $\left(\mathrm{CH}_{4}\right)$ to $0.5 \mathrm{sccm}$, lower defect density at the nucleation site can be obtained in a similar way. After thermal oxidation, $\mathrm{Cu}$ oxide is not visible at nucleation sites, as shown both in optical (Figure 5 e) and SEM images (Figure $5 \mathrm{f}$ ) - however some cracks are visible in the individual graphene grains, most likely due to thermal stress ${ }^{33}$. These observations highlight the difference in the nucleation process occurring over the $\mathrm{Cu}$ surface, here leading to a perfect nucleation and growth which is schematically shown in Figure $5 a$ and $b$.

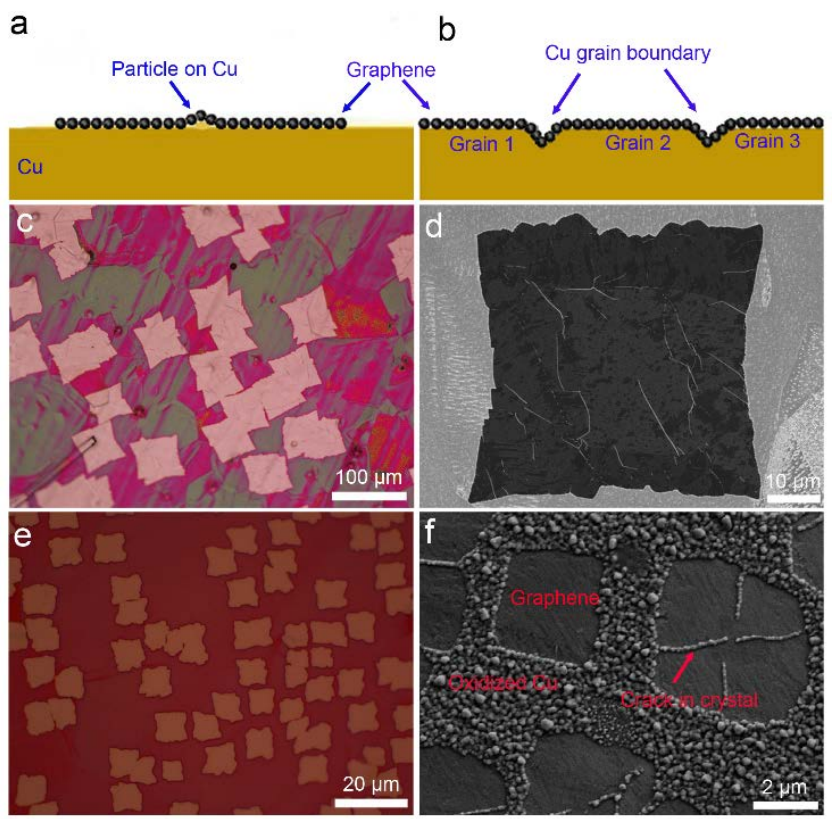

Figure 5. (a, b) Schematic side view of perfect nucleation and growth of graphene on the Cu surface. (c, d) Optical and SEM image of graphene grains synthesized by increasing the growth temperature $\left(1000^{\circ} \mathrm{C}\right)$ for the growth. (e, f) Optical and SEM image of graphene grains synthesized by reducing the flow rate of $\mathrm{CH}_{4}$ to $0.5 \mathrm{sccm}$ for the growth. The annealing has been applied in the air for $20 \mathrm{~min}$ at $250{ }^{\circ} \mathrm{C}$ for all the observations.

\section{CONCLUSION}

In conclusion, we have systematically studied the relationship between CVD graphene nucleation and associated influence on the oxidation of as synthesized graphene on $\mathrm{Cu}$ surface. Using optical microscopy combined with thermal annealing in air, we find that the initial stage of nucleation has a pronounced influence on the degree and distri- bution of defects in the graphene domains, which we ascribe to the different gas phase and thermodynamic equilibrium associated with CVD conditions. These defects would serve as a channel for the interfacial diffusion of $\mathrm{O}_{2}$ during the thermal annealing, transforming the oxidation of $\mathrm{Cu}$ gradually from nucleation center towards the growth edge in a pattern that reflects the structural quality and orientation of the graphene flake. By optimizing the growth conditions (reducing the flow rate of feedstock or increasing the growth temperature in our experiments), high quality graphene can be grown on $\mathrm{Cu}$ surface with no oxidation occurring at the nucleation sites. The anisotropic distribution of defected graphene which we observe at nucleation centers points to a heretofore unrevealed nucleation mechanism of graphene dependent on higher order hydrocarbons in the gas phase, and has important implications for the oxidation resistance of $\mathrm{Cu}$-coated graphene, and more generally for CVD graphene as a barrier layer. In addition, such oxidation experiments represent a rapid and facile means of monitoring the quality of CVD grown of graphene directly on the growth catalyst using only an optical microscope.

\section{ASSOCIATED CONTENT}

\section{Supporting Information.}

Additional Images, spectra and schematic model. This material is available free of charge via the Internet at http://pubs.acs.org.

\section{AUTHOR INFORMATION}

\section{Corresponding Author \\ *Email: Tim.Booth@nanotech.dtu.dk Notes}

The authors declare no competing financial interest.

\section{ACKNOWLEDGMENT}

We acknowledge the support from the EU Seventh Framework Programme $\left(\mathrm{FP}_{7} /\right.$ 2007-2013) under grant agreement number $\mathrm{FP}_{7-6040007}$ "GLADIATOR" and the EC Graphene FET Flagship, grant agreement number 604391,, and the Danish National Research Foundation Center of Excellence for Nanostructured Graphene (CNG), project DNRFioz.

\section{REFERENCES}

(1). Zhou, H.; Yu, W. J.; Liu, L.; Cheng, R.; Chen, Y.; Huang, X.; Liu, Y.; Wang, Y.; Huang, Y.; Duan, X., Chemical vapour deposition growth of large single crystals of monolayer and bilayer graphene. Nat. Commun 2013, 4, 2096-2103.

(2). Yu, Q.; Jauregui, L. A.; Wu, W.; Colby, R.; Tian, J.; Su, Z.; Cao, H.; Liu, Z.; Pandey, D.; Wei, D., Control and characterization of individual grains and grain boundaries in graphene grown by chemical vapour deposition. Nat. Mater 2011, 10, 443-449.

(3). Wang, H.; Wang, G.; Bao, P.; Yang, S.; Zhu, W.; Xie, X.; Zhang, W.-J., Controllable synthesis of submillimeter singlecrystal monolayer graphene domains on copper foils by suppressing nucleation. J. Am. Chem. Soc. 2012, 134, 3627-3630.

(4). Eres, G.; Regmi, M.; Rouleau, C. M.; Chen, J.; Ivanov, I. N.; Puretzky, A. A.; Geohegan, D. B., Cooperative island growth of large-area single-crystal graphene on copper using chemical vapor deposition. ACS Nano 2014, 8, 5657-5669. 
(5). Hao, Y.; Bharathi, M.; Wang, L.; Liu, Y.; Chen, H.; Nie, S.; Wang, X.; Chou, H.; Tan, C.; Fallahazad, B., The role of surface oxygen in the growth of large single-crystal graphene on copper. Science 2013, 342, 720-723.

(6). Gan, L.; Luo, Z., Turning off hydrogen to realize seeded growth of subcentimeter single-crystal graphene grains on copper. ACS Nano 2013, 7, 9480-9488.

(7). Nguyen, V. L.; Shin, B. G.; Duong, D. L.; Kim, S. T.; Perello, D.; Lim, Y. J.; Yuan, Q. H.; Ding, F.; Jeong, H. Y.; Shin, H. S., Seamless stitching of graphene domains on polished copper (111) Foil. Adv. Mater. 2015, 27, 1376-1382.

(8). Cho, S.-Y.; Kim, M.-S.; Kim, M.; Kim, K.-J.; Kim, H.M.; Lee, D.-J.; Lee, S.-H.; Kim, K.-B., Self-assembly and continuous growth of hexagonal graphene flakes on liquid $\mathrm{Cu}$. Nanoscale 2015, 7, 12820-12827.

(9). Lee, J.-H.; Lee, E. K.; Joo, W.-J.; Jang, Y.; Kim, B.-S.; Lim, J. Y.; Choi, S.-H.; Ahn, S. J.; Ahn, J. R.; Park, M.-H., Waferscale growth of single-crystal monolayer graphene on reusable hydrogen-terminated germanium. Science 2014, 344, 286-289.

(10). Vlassiouk, I.; Smirnov, S.; Ivanov, I.; Fulvio, P. F.; Dai, S.; Meyer, H.; Chi, M.; Hensley, D.; Datskos, P.; Lavrik, N. V., Electrical and thermal conductivity of low temperature CVD graphene: the effect of disorder. Nanotechnology 2011, 22, 275716-275725

(11). Huang, P. Y.; Ruiz-Vargas, C. S.; van der Zande, A. M.; Whitney, W. S.; Levendorf, M. P.; Kevek, J. W.; Garg, S.; Alden, J. S.; Hustedt, C. J.; Zhu, Y., Grains and grain boundaries in singlelayer graphene atomic patchwork quilts. Nature 2011, 469, 389392.

(12). Hayashi, K.; Sato, S.; Yokoyama, N., Anisotropic graphene growth accompanied by step bunching on a dynamic copper surface. Nanotechnology 2013, 24, 025603-025610.

(13). Gao, J.; Yip, J.; Zhao, J.; Yakobson, B. I.; Ding, F., Graphene nucleation on transition metal surface: Structure transformation and role of the metal step edge. J. Am. Chem. Soc. 2011, 133, 5009-5015.

(14). Han, G. H.; Günes, F.; Bae, J. J.; Kim, E. S.; Chae, S. J.; Shin, H.-J.; Choi, J.-Y.; Pribat, D.; Lee, Y. H., Influence of copper morphology in forming nucleation seeds for graphene growth. Nano Lett. 2011, 11, 4144-4148.

(15). Ghosh, P.; Kumar, S.; Ramalingam, G.; Kochat, V.; Radhakrishnan, M.; Dhar, S.; Suwas, S.; Ghosh, A.; Ravishankar, N.; Raghavan, S., Insights on defect-mediated heterogeneous nucleation of graphene on copper. J. Phys. Chem. C. 2015, 119, 2513-2522.

(16). Suzuki, S.; Nagamori, T.; Matsuoka, Y.; Yoshimura, M., Threefold atmospheric-pressure annealing for suppressing graphene nucleation on copper in chemical vapor deposition. Jpn. J. Appl. Phys. 2014, 53, 095101-095106.

(17). Hafiz, S. M.; Chong, S. K.; Huang, N. M.; Rahman, S. A., Fabrication of high-quality graphene by hot-filament thermal chemical vapor deposition. Carbon 2015, 86, 1-11.

(18). Trinsoutrot, P.; Rabot, C.; Vergnes, H.; Delamoreanu, A.; Zenasni, A.; Caussat, B., The role of the gas phase in graphene formation by CVD on copper. Chem. Vapor Depos. 2014, 20, 5158.

(19). Wu, B.; Geng, D.; Xu, Z.; Guo, Y.; Huang, L.; Xue, Y.; Chen, J.; Yu, G.; Liu, Y., Self-organized graphene crystal patterns. NPG Asia Mater. 2013, 5, e36-e43.
(20). Li, Z.; Zhang, W.; Fan, X.; Wu, P.; Zeng, C.; Li, Z.; Zhai, X.; Yang, J.; Hou, J., Graphene thickness control via gas-phase dynamics in chemical vapor deposition. J. Phys. Chem. C. 2012, 116, 10557-10562.

(21). Lewis, A. M.; Derby, B.; Kinloch, I. A., Influence of gas phase equilibria on the chemical vapor deposition of graphene. ACS Nano 2013, 7, 3104-3117.

(22). Chen, S.; Ji, H.; Chou, H.; Li, Q.; Li, H.; Suk, W. J.; Piner, R.; Liao, L.; Cai, W.; Ruoff, R. S., Millimeter-size singlecrystal graphene by suppressing evaporative loss of $\mathrm{Cu}$ during low pressure chemical vapor deposition. Adv. Mater. 2013, 25, 20622065.

(23). Wang, Y.; Zheng, Y.; Xu, X.; Dubuisson, E.; Bao, Q.; Lu, J.; Loh, K. P., Electrochemical delamination of CVD-grown graphene film: toward the recyclable use of copper catalyst. ACS Nano 2011, 5, 9927-9933.

(24). Gao, L.; Ren, W.; Xu, H.; Jin, L.; Wang, Z.; Ma, T.; Ma, L.-P.; Zhang, Z.; Fu, Q.; Peng, L.-M., Repeated growth and bubbling transfer of graphene with millimetre-size single-crystal grains using platinum. Nat. Commun. 2012, 3, 699-706.

(25). Bunch, J. S.; Verbridge, S. S.; Alden, J. S.; van der Zande, A. M.; Parpia, J. M.; Craighead, H. G.; McEuen, P. L., Impermeable atomic membranes from graphene sheets. Nano Lett. 2008, 8, 2458-2462.

(26). Duong, D. L.; Han, G. H.; Lee, S. M.; Gunes, F.; Kim, E. S.; Kim, S. T.; Kim, H.; Ta, Q. H.; So, K. P.; Yoon, S. J., Probing graphene grain boundaries with optical microscopy. Nature 2012, 490, 235-239.

(27). Zhang, Y.; Wang, B.; Zhang, H.; Chen, Z.; Zhang, Y.; Sui, Y.; Li, X.; Xie, X.; Yu, G.; Jin, Z., The distribution of wrinkles and their effects on the oxidation resistance of chemical vapor deposition graphene. Carbon 2014, 70, 81-86

(28). Larsen, M. B. B.; Mackenzie, D. M.; Caridad, J. M.; Bøggild, P.; Booth, T. J., Transfer induced compressive strain in graphene: Evidence from Raman spectroscopic mapping. Microelectron. Eng. 2014, 121, 113-117.

(29). Li, X.; Zhang, G.; Bai, X.; Sun, X.; Wang, X.; Wang, E.; Dai, H., Highly conducting graphene sheets and LangmuirBlodgett films. Nat. Nanotechnol 2008, 3, 538-542.

(30). Kim, H.; Mattevi, C.; Calvo, M. R.; Oberg, J. C.; Artiglia, L.; Agnoli, S.; Hirjibehedin, C. F.; Chhowalla, M.; Saiz, E., Activation energy paths for graphene nucleation and growth on $\mathrm{Cu}$. ACS Nano 2012, 6, 3614-3623.

(31). Zhang, Y.; Zhang, H.; Li, F.; Shu, H.; Chen, Z.; Sui, Y.; Zhang, Y.; Ge, X.; Yu, G.; Jin, Z., Invisible growth of microstructural defects in graphene chemical vapor deposition on copper foil. Carbon 2016, 96, 237-242.

(32). Wu, R.; Gan, L.; Ou, X.; Zhang, Q.; Luo, Z., Detaching graphene from copper substrate by oxidation-assisted water intercalation. Carbon 2016, 98, 138-143.

(33). Kalita, G.; Papon, R.; Sharma, S.; Shinde, S. M.; Vishwakarma, R.; Tanemura, M., Transformation of chemical vapor deposited individual graphene crystal with oxidation of copper substrate. Carbon 2014, 80, 504-512. 


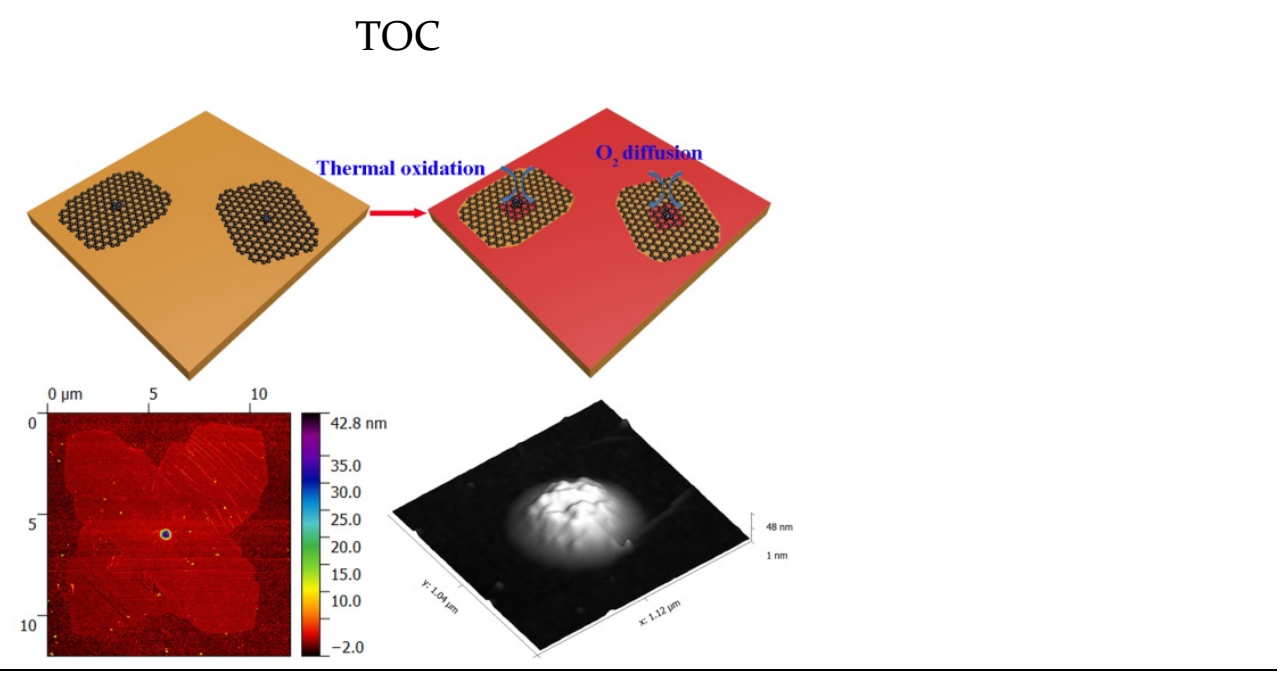

